\title{
The duration and perceived intensity of sucrose taste
}

\author{
HARRY T. LAWLESS \\ Walter S. Hunter Laboratory of Psychology, Brown University, Providence, Rhode Island 02912
}

and

\author{
ELAINE Z. SKINNER \\ General Foods Technical Center, White Plains, New York 10625
}

\begin{abstract}
Thirty-two subjects judged the perceived intensity of each of four concentrations of sucrose over 2 min. Stimuli were either sipped and expectorated or flowed over the subject's extended tongue. Ratio judgments on a line scale and category ratings were made. Sixteen of the subjects had had extensive training in judging the sensory attributes of food products, and another group of 16 subjects were untrained. The perceived intensity of sucrose rose to a peak within 5 or $10 \mathrm{sec}$, and then declined over $2 \mathrm{~min}$. In both the sip and the flow conditions, the taste disappeared completely for 26 of 32 subjects. Stronger concentrations were perceived as having greater peak intensities and longer lasting taste. The differences between concentrations were enhanced when sipped rather than flowed over the tongue. Judgments of intensity and duration were largely unaffected by the training level of subjects and the use of different rating scales.
\end{abstract}

One important attribute of sapid substances is the time course of the sensations they elicit. Artificial sweeteners, for example, often have persistent aftertastes which detract from their palatability. Despite the importance of sucrose as a sweetener, few experiments have investigated the time course of sucrose taste (Meiselman, 1968). Instead, recent studies have been concerned with the related issues of individual differences in the completeness of gustatory adaptation (DuBose, Meiselman, Hunt, \& Waterman, 1977; Gent \& McBurney, 1978; Meiselman, 1975) and sensitivity to changes in concentration over time (McBurney, 1976).

The present experiment had two purposes. First, the time course of the perceived intensity of sucrose was described. Second, variables which might affect this time course were investigated. These included concentration, rating method, the training level of subjects, and stimulus presentation procedure. In one procedure, samples were sipped and expectorated. This provided stimulation resembling that of eating, but avoided postingestional effects (Mower, Maier, \& Engen, 1977). In addition, stimuli were flowed over the tongue (McBurney \& Pfaffmann, 1963). The flow condition was included to assess the course of sensory adaptation with better control over temperature, tactile stimulation, and the spatial

H. T. Lawless is now at the Behavioral Sciences Division, Food Sciences Laboratory, DRDNA-YB, U.S. Army Natick Research and Development Command, Natick, Massachusetts 01760. Reprint requests should be sent to Elaine Z. Skinner, General Foods Technical Center, White Plains, New York 10625. pattern of stimulation. Previously, flow procedures had been used to study the time course of neural adaptation (Sato, 1971; Wang \& Bernard, 1970) and adaptation in humans using psychophysical procedures (DuBose et al., 1977; Gent \& McBurney, 1978).

This experiment also provided an opportunity to study the completeness of gustatory adaptation. Some investigators have reported complete loss of taste sensations when stimuli are flowed over the tongue (Zotterman, 1971; see also Pfaffmann, Bartoshuk, \& McBurney, 1971). However, Meiselman (1975) has argued that there are large individual differences in the tendency to adapt, and that complete adaptation is often not observed (see DuBose et al., 1977).

\section{METHOD}

\section{General}

Each subject participated in four sessions. Each session combined one of two rating methods, category scaling or ratio scaling, with one of two tasting procedures, sip and spit or dorsal flow. In each session, the subjects tasted four concentrations of sucrose and then the same four stimuli in reverse order for a total of eight trials. In addition, the 32 subjects were divided into two groups, trained and untrained tasters.

\footnotetext{
Subjects

Thirty-five subjects volunteered, 17 trained taste panelists and 18 untrained tasters. All were employees of the General Foods Corporation and all had had some experience with simple taste tests. Three subjects dropped out, leaving 16 trained (7 male) and 16 untrained (8 male) tasters. The trained tasters had had training and experience in describing the sensory attributes of one or more food products, such as coffee.
} 


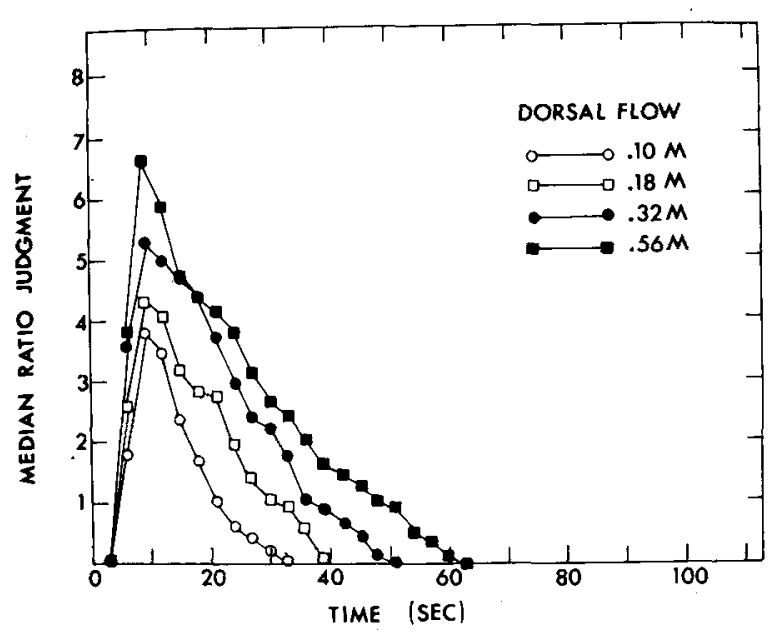

Figure 1. Median ratio judgments of taste intensity from all 32 subjects (after the two replicates were averaged) plotted against time. Stimuli were flowed over the subject's extended tongue. Time $=$ zero corresponds to the experimenter turning the valve in the flow system and cueing the subject.

\section{Stimuli}

Sucrose solutions were prepared from commercial grade sucrose in spring water (Pine Hill Crystal Spring Water Co.), in the following concentrations: $.10, .18, .32$, and $.56 \mathrm{M}$.

\section{Presentation}

Stimuli were presented in two ways. In the sip-and-spit condition, the stimuli were $10-\mathrm{ml}$ samples in $30-\mathrm{ml}$ cups at room temperature. The subjects rinsed before each stimulus. In the dorsal flow condition, the stimuli flowed over the dorsal anterior third of the subject's extended tongue after a 10-sec water rinse. The temperature of the solutions was $34^{\circ} \mathrm{C}$, the flow rate was $3 \mathrm{ml} / \mathrm{sec}$, and the duration of each stimulus was 2 min or until the subject signaled absence of sensation for 15-20 consecutive sec, whichever came first.

\section{Rating Methods}

In one condition, the subjects assigned category ratings to taste intensity using an 11-point scale, chosen to resemble a rating scale commonly used at General Foods. The following verbal descriptors were provided: no sensation (0), threshold (1), weak (3), moderate (6), strong (9), and very strong (10). In the sip-and-spit condition, the subjects were given ballots with numbered spaces for intensity ratings. On verbal command from the experimenter, ratings were recorded on the ballot at the following intervals: $5,15,20,25,30,40,50,60,70,80,90,100,110,120,130,140$, and $150 \mathrm{sec}$. There was no rating made at $10 \mathrm{sec}$, when the subjects expectorated. In the dorsal flow condition, the subjects moved a pointer on a dial to indicate taste intensity. The same 11-point scale was used, with approximately equal areas on the dial for each category. Ratings were recorded at the same intervals as in the sip-and-spit condition, except that the 10 -sec interval was included and the 150 -sec interval omitted. In both presentation procedures, the subjects judged pleasantness at the end of each trial. They gave a rating for the entire taste sensation, using a 7-point scale, -3 signifying strong unpleasantness and +3 strong pleasantness.

In the ratio scaling condition, the subjects moved a pointer along a line scale $26 \mathrm{~cm}$ in length with a zero mark at one end. They were instructed to move the pointer to mark off a distance from zero proportional to the taste intensity. They were told to estimate ratios, so that if the taste intensity doubled from some level, the pointer would be moved twice as far from zero. Similarly, the subjects were instructed to preserve ratio properties between stimuli, such that if the second stimulus was half as strong at its peak as the first, the pointer would be moved half as far from zero. The pointer was connected to the pen of a chart recorder (Hewlett-Packard, 7127A) providing a continuous record of taste intensity. The subjects also rated the overall pleasantness at the end of each trial, using a bipolar pleasantness scale with a plus over one end, a minus over the other, and a zero in the middle. They moved the pointer to a position whose distance from zero represented the magnitude of the pleasantness or unpleasantness of each stimulus.

\section{RESULTS AND DISCUSSION}

Separate analyses of variance were performed on the peak intensity judgments from ratio and category scaling. A third analysis was performed on the time it took the perceived intensity of a stimulus to fall to one-half its peak. No attempt was made to analyze the differences in the rise time of sensation. The response latency in the ratio scaling condition was approximately $3 \mathrm{sec}$, a lag which probably obscured the fine detail of the onset of sensation.

The functions for taste intensity over time are shown in Figures 1-4 for the four combinations of rating methods and presentation procedures. These are plots of medians taken after the two judgments of a given concentration within a session were averaged. The curves of trained and untrained tasters were not different in the time it took sensation to decay to half-maximum, and were combined. The taste of sucrose rose rapidly, peaked within $10 \mathrm{sec}$, and then declined. The taste usually disappeared within 2 min.

The decline in perceived intensity was fit by an exponential function of the form $R=a e^{-b t}$, where $R=$ perceived intensity, $b=$ the rate constant (the

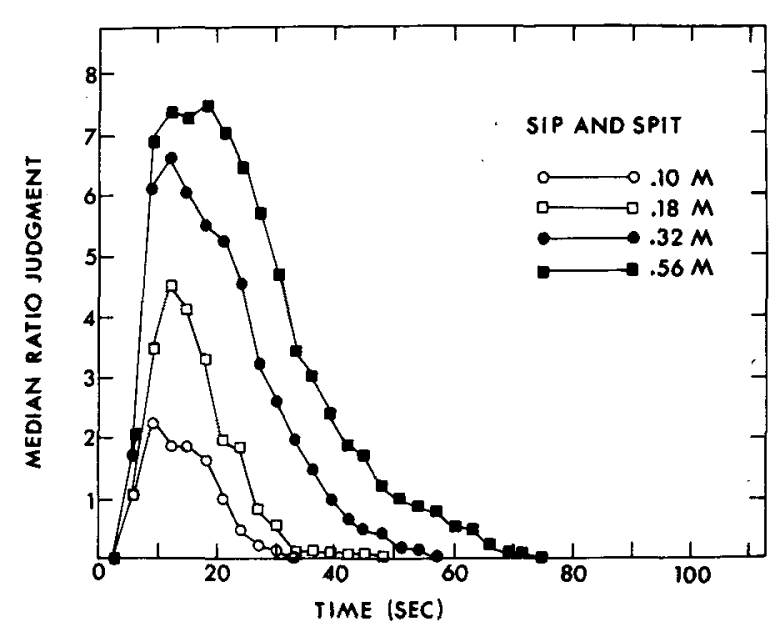

Figure 2. Median ratio judgments of taste intensity from all 32 subjects (after the two replicates were averaged) plotted against time. Stimuli were sipped and expectorated after $10 \mathrm{sec}$. Time = zero corresponds to the verbal command of the experimenter to sip. 


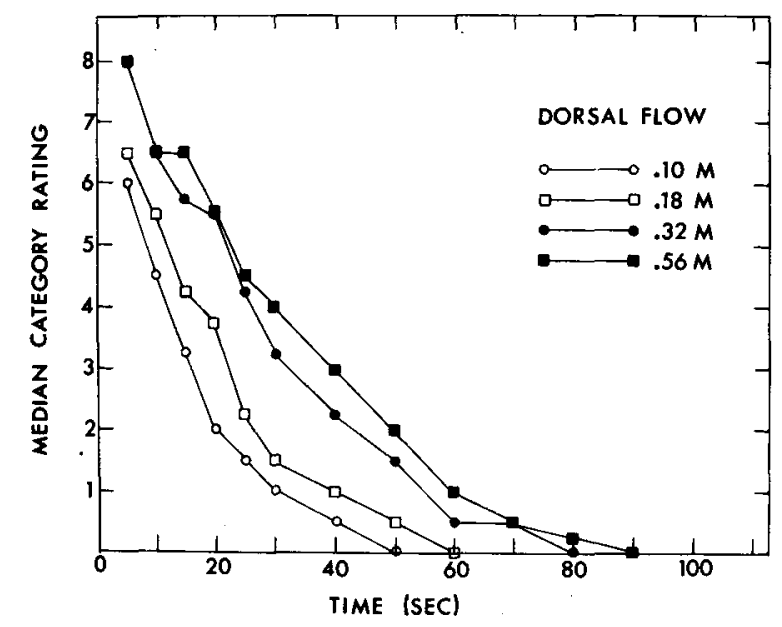

Figure 3. The median category ratings of taste intensity plotted against time. Stimuli were flowed over the subject's extended tongue.

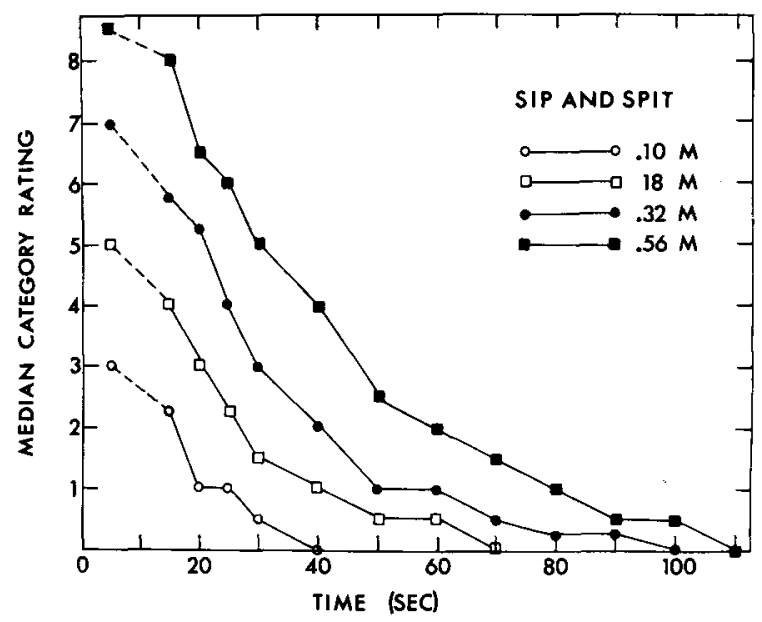

Figure 4. Median category ratings of taste intensity plotted against time. Stimuli were sipped and expectorated after 10 see. No judgment was required during expectoration.

reciprocal of the time it takes $R$ to reach $1 / \mathrm{e}$ of its extrapolated initial value, and $\mathrm{a}=$ constant. The values for the rate constant are shown in Table 1 . A second major characteristic of these functions was the orderly variation with concentration. Not surprisingly, stronger concentrations were judged to have greater peak intensities and to last longer. The effect of concentration on peak taste intensity was highly significant $[F(3,479)=123.7$ for ratio scaling and 123.6 for category scaling, $p<.001]$. There was also an effect of concentration on duration, as indicated by the rate constants in Table 1 , and a significant effect of concentration on the time for perceived intensity to decay to one-half its peak value $[F(3,90)=24.1, p<.001]$.

One important result in the dorsal flow condition was the completeness of adaptation. Twenty-six subjects reported zero taste intensity within $2 \mathrm{~min}$ on the ratio scaling task. Three subjects did not completely adapt to at least one concentration, and three others remained above $25 \%$ of their peak intensity rating on at least two of the concentrations. Other experiments have found fewer subjects who completely adapt (DuBose et al., 1977; Meiselman, 1975; Meiselman \& DuBose, 1976). This discrepancy could be the result of differences in response task, flow rate, temperature, or the use of a tongue fixation apparatus. Gent and McBurney (1978) found relatively complete adaptation when stimulating the tongue with filter paper soaked in a taste solution. This method provides a relatively stable spatial distribution of the stimulus and suggests that changes in concentration over different areas of the tongue (as occurs in sip-and-spit procedures) might hinder complete adaptation.

Several effects were noted as a result of the different presentation methods. First, the stimuli in the sipand-spit condition had longer durations $[F(1,30)=$ $6.81, \mathrm{p}<.05]$, even though the flow system insured a more stable concentration on the tongue and no dilution by saliva. Since the tongue was held relatively still under the flow, but allowed to move in the sip-and-spit condition, tongue movements may have played a part in prolonging taste sensations. These procedures differed in solution temperature $\left(34^{\circ}\right.$ vs. $\left.21^{\circ} \mathrm{C}\right)$, which could also have contributed to the observed differences. Another important effect was the greater difference between concentrations in the sip-and-spit condition. The peak heights were farther apart, as shown by significant interactions of concentration with presentation procedure $[F(3,479)=14.52$ and 15.52 for ratio and category ratings, respectively, $\mathrm{p}<.001]$.

This interaction can also be seen in the psychophysical functions for the two methods. The functions for peak intensity against concentration are shown in Figure 5. The sip-and-spit functions are much steeper. Power functions (Stevens, 1969) were fit to two measures of intensity, the peak judgment and the total area under the curve for intensity against time. The exponents of these power functions are shown in Table 2 . By either measure, the psycho-

Table 1

Exponential Function Rate Constants

\begin{tabular}{lcccc}
\hline & \multicolumn{4}{c}{ Concentration (M) } \\
\cline { 2 - 5 } Session & .10 & .18 & .32 & .56 \\
\hline Dorsal Flow & & & & \\
$\quad$ Ratio Scale & $.142(.98)$ & $.075(.96)$ & $.086(.86)$ & $.065(.86)$ \\
$\quad$ Category Scale & $.072(.99)$ & $.059(.99)$ & $.044(.96)$ & $.046(.96)$ \\
Sip and Spit & & & & \\
$\quad$ Ratio Scale & $.152(.91)$ & $.115(.91)$ & $.085(.95)$ & $.040(.92)$ \\
$\quad$ Category Scale & $.071(.95)$ & $.048(.97)$ & $.043(.98)$ & $.032(.98)$ \\
\hline
\end{tabular}

Note-Numbers in parentheses are values for $r^{2}$. 


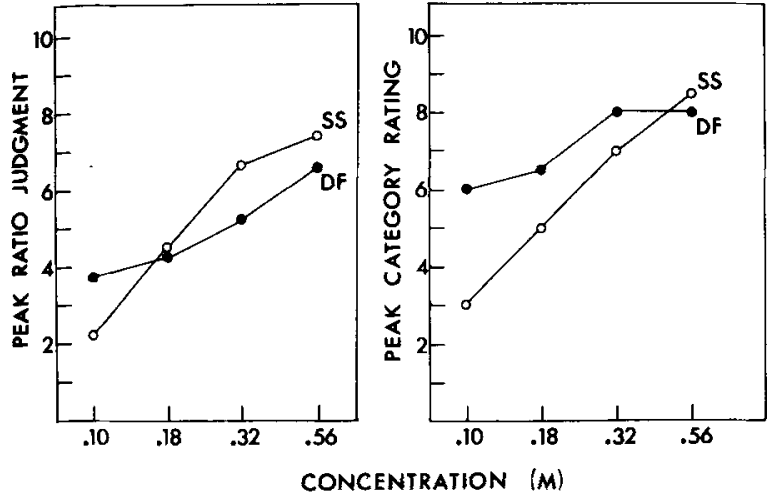

Figure 5. Median peak intensity judgments plotted against concentration. Note that the abscissa is logarithmic. ( $\mathrm{SS}=$ sip-andspit presentation, $\mathrm{DF}=$ dorsal flow presentation.)

Table 2

Power Function Exponents

\begin{tabular}{lccccc}
\hline & $\begin{array}{c}\text { Median Peak Height } \\
\text { Against Concentration }\end{array}$ & & $\begin{array}{l}\text { Area Under the } \\
\text { Time-Intensity } \\
\text { Curve Against } \\
\text { Concentration }\end{array}$ \\
\cline { 2 - 3 } \cline { 5 - 6 } Session & $\mathrm{E}$ & $\mathrm{r}^{2}$ & & $\mathrm{E}$ & $\mathrm{r}^{2}$ \\
\hline $\begin{array}{l}\text { Dorsal Flow } \\
\text { Ratio Scale }\end{array}$ & .34 & .99 & .70 & .99 \\
Category Scale & .19 & .90 & .61 & .96 \\
$\begin{array}{l}\text { Sip and Spit } \\
\text { Ratio Scale }\end{array}$ & .69 & .90 & 1.16 & .98 \\
Category Scale & .60 & .96 & 1.11 & .98 \\
\hline
\end{tabular}

Note-r $r^{2}$ calculated from group curves only, not individual data; $E=$ Exponent.

physical functions have lower exponents (are more compressed) in the dorsal flow procedure, an effect previously discussed by Meiselman (1971).

Do subjects judge peak taste intensity or consider taste intensity over time in psychophysical scaling experiments? The results in Table 2 indicate that higher exponents may be obtained when time course is considered as well as peak taste intensity. The exponents generated from functions of area (under the curve) against concentration are closer to values found in other studies (see Meiselman, 1971).

The category scaling and ratio scaling tasks produced similar results. The ratio scaling was coupled to the chart recorder, and therefore produced a more detailed account. The category scaling produced slightly longer durations. This may have been due to the willingness of subjects to use the "threshold" category. As shown in Table 2, the category ratings also produced psychophysical functions with shallower slopes, an effect noted by Stevens and Galanter (1957).

Several other small, but significant, effects were found. There were few differences in the timeintensity curves for trained tasters and untrained subjects. However, the trained tasters gave higher peak category ratings in the dorsal flow condition and higher peak ratio judgments in sip and spit. These effects were shown by a Training Level by Presentation Method interaction for the peak taste intensities $[F(1,479)=15.92$ and 12.42 for category ratings and ratio judgments, respectively, $\mathrm{p}<.001]$. There was also a tendency for the second ratio judgment in a session to be given a higher peak value $[F(1,479)=19.81]$, especially at higher concentrations $[F(3,479)=3.87]$, and by untrained tasters $[F(1,479)=9.65 ; p<.01$ in all cases $]$. However, these effects did not reach significance in the analysis of the time it took perceived intensity to decay to one-half its peak value.

The pleasantness judgments are shown for the different sessions and concentrations in Figure 6. These functions show the classic inverted-U-shaped function for pleasantness against concentration (Moskowitz, 1971). There was a trend for the second judgment in a session to be judged as less pleasant $[F(1,479)=4.42$ and 5.40 for ratio judgments and category ratings, respectively, $\mathrm{p}<.05$ ]. The trained tasters gave higher category ratings than the untrained observers $[F(1,479)=10.53, \mathrm{p}<.005]$. It was surprising that the group data showed peak pleasantness at $.18 \mathrm{M}$ sucrose, much lower than had been previously reported (Moskowitz, 1971). The subjects objected to the extended exposure to moderately strong sucrose.

In summary, the time course of sucrose taste was characterized by a rapid rise to peak intensity and a rapid decline, ending in complete adaptation. More concentrated solutions rose to higher peak intensities and were tasted longer. When stimuli were sipped and expectorated, rather than flowed over the tongue, the differences between concentrations were accentuated. The training level of subjects and the use of different scaling methods made only small differences in the form of the time-intensity functions.

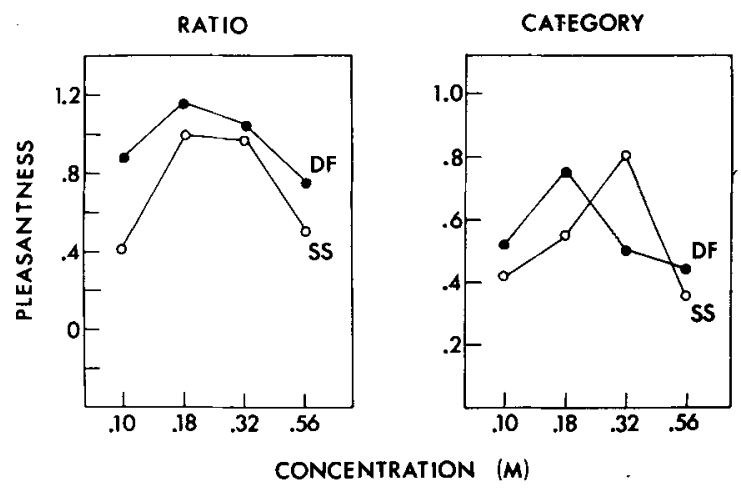

Figure 6. The mean pleasantness ratings plotted against concentration. Note that the abscissa is logarithmic. (SS = sip-and-spit presentation, $\mathrm{DF}=$ dorsal flow presentation.) 


\section{REFERENCES}

DuBose, C. N., Meiselman, H. L., Hunt, D. A., \& Waterman, D. Incomplete taste adaptation to different concentrations of salt and sugar solutions. Perception \& Psychophysics, 1977, 21, 183+186.

GENT, J. F., \& MCBuRney, D. H. Time course of gustatory adaptation. Perception \& Psychophysics, 1978, 23, 171-175.

MCBURNEY, D. H. Temporal properties of the human taste system. Sensory Processes, 1976, 1, 150-162.

McBurney, D. H., \& Pfaffmann, C. Gustatory adaptation to saliva and sodium chloride. Journal of Experimental Psychology, 1963, 65, 523-529.

Meiserman, H. L. Magnitude estimations of the course of gustatory adaptation. Perception \& Psychophysics, 1968, 4, 193-196.

Meiselman, $H$. L. Effect of presentation procedure on taste intensity functions. Perception \& Psychophysics, 1971, 10, 15-18.

Meiselman, H. Effect of response task on taste adaptation. Perception \& Psychophysics, 1975, 17, 591-595.

Meiselman, H. L., \& DuBose, C. N. Failure of instructional set to affect completeness of taste adaptation. Perception \& Psychophysics, 1976, 19, 226-230.

Moskowitz, H. R. The sweetness and pleasantness of sugars. American Journal of Psychology, 1971, 84, 387-405.
MoWer, G. D., MAIR, R., \& ENGEN, T. Influence of internal factors on the perceived intensity and pleasantness of gustatory and olfactory stimuli. In M. R. Kare \& $O$. Maller (Eds.), The chemical senses and nutrition. New York: Academic Press, 1977.

Pfaffmann, C., Bartoshuk, L. M., \& McBurney, D. H. Taste psychophysics. In L. M. Beidler (Ed.), Handbook of sensory physiology[Vol. 4(2)]. New York: Springer-Verlag, 1971.

SATo, T. Site of gustatory neural adaptation. Brain Research, 1971, 34, 385-388.

Stevens, S. S. Sensory scales of taste intensity. Perception \& Psychophysics, 1969, 6, 302-308.

Stevens, S. S., \& Galanter, E. H. Ratio scales and category scales for a dozen perceptual continua. Journal of Experimental Psychology, 1957, 54, 377-411.

Wang, M. B., \& Bernard, R. A. Adaptation of neural taste responses in cat. Brain Research, 1970, 20, 277-282.

ZotTERMaN, Y. The recording of electrical response from human taste nerves. In L. M. Beidler (Ed.), Handbook of sensory physiology [Vol. 4(2)]. New York: Springer-Verlag, 1971.

(Received for publication June 19, 1978; revision accepted November 18, 1978.)

\section{ERRATUM}

Leibowitz, H. W., Rodemer, C. S., \& Dichgans, J. The independence of dynamic spatial orientation from luminance and refractive error (Perception \& Psychophysics, 1979, 25, 75-79) - The first sentence of the Discussion section on page 77 should correctly read: "The data of the present study demonstrate that there is essentially no relationship between luminance level or refractive error and the time to onset of circularvection, the time to full saturation, or the duration of the aftereffect." The second sentence of the past paragraph on page 78 should correctly read: "The independence of orientation and localization mechanisms from luminance level permits the system to operate efficiently over the dynamic luminance range of visual stimulation." 